\title{
Infiltrating and peripheral immune cell analysis in advanced gastric cancer according to the Lauren classification and its prognostic significance
}

\author{
Simon Pernot ${ }^{1,2}$ (1) $\cdot$ Magali Terme $^{1} \cdot$ Nina Radosevic-Robin ${ }^{3} \cdot$ Florence Castan $^{4} \cdot$ Cécile Badoual $^{1,5} \cdot$ Elie Marcheteau $^{1}$. \\ Fréderique Penault-Llorca ${ }^{3}$. Olivier Bouche ${ }^{6}$. Jaafar Bennouna ${ }^{7}$. Eric Francois ${ }^{8}$. Francois Ghiringhelli ${ }^{9}$. \\ Christelle De La Fouchardiere ${ }^{10}$. Emmanuelle Samalin ${ }^{11}$. Jean Baptiste Bachet ${ }^{12} \cdot$ Christophe Borg $^{13}$. \\ Valérie Boige $^{14} \cdot$ Thibault Voron $^{1} \cdot$ Trevor Stanbury $^{15} \cdot$ Eric Tartour $^{1} \cdot$ Sophie Gourgou $^{4} \cdot$ David Malka $^{14}$. \\ Julien Taieb ${ }^{1,2}$
}

Received: 20 February 2019 / Accepted: 25 June 2019 / Published online: 2 July 2019

(c) The International Gastric Cancer Association and The Japanese Gastric Cancer Association 2019

\begin{abstract}
Background The correlation between immune cells and the Lauren classification subtypes and their prognostic impact in advanced gastric cancer (AGC) are unknown.

Methods Circulating natural killer (NK) cells, $\mathrm{CD}^{+}$and $\mathrm{CD} 8^{+} \mathrm{T}$ cells, regulatory $\mathrm{T}$ cells (Tregs) and myeloid-derived suppressor cells (MDSCs) were quantified in peripheral blood mononuclear cells (PBMCs) from 67 patients with untreated AGC enrolled in the PRODIGE 17-ACCORD 20 trial. CD56 ${ }^{+}$cells (NK), CD8 ${ }^{+}$, and FoxP3 ${ }^{+}$(Treg) tumor-infiltrating lymphocytes (TILs) were assessed in tumor samples.

Results Circulating NK and Treg proportions were significantly lower in patients with diffuse/mixed-type AGC $(n=27)$ than those with intestinal type ( $n=40$; median $6.3 \%$ vs $11.5 \% ; p=0.02$ and median $3.3 \%$ vs $5.2 \% ; p=0.03$, respectively). Proportions of circulating MDSC, $\mathrm{CD} 4^{+}$and $\mathrm{CD} 8^{+} \mathrm{T}$ cells were not associated with one pathological type. Among tumorinfiltrating cells, $\mathrm{CD} 8^{+} \mathrm{T}$ cells, but not $\mathrm{NK}$ or FoxP3 ${ }^{+}$cells, were significantly lower in diffuse/mixed-type AGC (median 21 vs 59 cells/field; $p=0.009)$. Patients with high circulating NK cell counts $(>17 \%)$ had a better overall survival than those with $<17 \%$ (HR 0.40; 95\% CI [0.15-1.06]; $p=0.04$ ). Patients with high CD8 ${ }^{+}$TIL counts ( $>31$ cells/field) had significantly longer overall survival (HR 0.44; $95 \%$ CI $[0.21-0.92] ; p=0.02$ ). The prognostic value of CD ${ }^{+}$TILs was maintained after adjustment for confounding factors, including the Lauren classification ( $\mathrm{HR}=0.42 ; 95 \% \mathrm{CI}[0.18-0.96] ; p=0.039)$.

Conclusion Diffuse/mixed-type AGC has lower rates of CD8 ${ }^{+}$TILs and circulating NK cells and Tregs than the intestinal type. This "cold tumor" phenotype may be associated with a worse outcome.
\end{abstract}

Keywords Advanced gastric adenocarcinoma $\cdot$ Biomarker $\cdot \mathrm{CD}^{+} \mathrm{T}$ lymphocytes $\cdot$ Natural killer cells $\cdot$ Regulatory $\mathrm{T}$ cells

Simon Pernot and Magali Terme contributed equally to this work.

Electronic supplementary material The online version of this article (https://doi.org/10.1007/s10120-019-00983-3) contains supplementary material, which is available to authorized users.

Simon Pernot

simon.pernot@aphp.fr

Extended author information available on the last page of the article

\section{Introduction}

Gastric cancer (GC) is the third leading cause of cancerrelated death in the world [1]. Immunity plays a key role in carcinogenesis and tumor progression, with immune modulation currently an important strategy for improving cancer therapy. Among effector cells, $\mathrm{CD}^{+} \mathrm{T}$ lymphocytes and natural killer cells (NK) play a major role in immunosurveillance. On the other hand, regulatory $\mathrm{T}$ cells (Tregs) and myeloid-derived suppressor cells (MDSCs) have emerged as an important contributor to tumor progression in different tumor types [2,3]. A higher density of immune cells in resected GC patients, in particular $\mathrm{CD} 8^{+} \mathrm{T}$ cells 
and NK, has been associated with more favorable clinical outcomes [4-7]. Despite immunotherapies being tested in advanced GC (AGC), little is known about the prognostic role of immune cells in these patients. It is important that data from resected GC studies are not extrapolated to AGC, since PD-L1 expression and infiltration of tumor-infiltrating lymphocytes (TILs) differ with disease stage [8] and with the development of immune escape mechanisms with metastatic progression [6, 7]. Moreover, during metastatic dissemination, TILs and circulating immune cells could present a different profile and different clinical significance [9]. Circulating cells may reflect the general immune status of the patient and probably its ability to mount or maintain an efficient immune response against the tumor. The presence of immune cells in the tumor is linked to their capacity to migrate into the tumor but also for $\mathrm{T}$ cells to their priming. The clinical significance of circulating cells has never been assessed to our knowledge in metastatic gastric cancer.

Clinical trials evaluating immune checkpoint blockade in AGC have yielded conflicting results. Phase I-III trials have shown interesting efficacy results with anti-PD-1, antiCTLA-4, and combination therapies [10-12]. However, both pembrolizumab and avelumab recently failed to extend survival in phase III trials, compared to chemotherapy, in pretreated AGC patients $[13,14]$. These controversial results highlight that not all AGC patients may benefit from immunotherapies and that careful identification and selection of patients will be required.

GC is a heterogeneous cancer with various forms depending on epidemiology, oncogenesis, pathology and molecular profile. The Lauren classification, the most widely used in clinical practice and trials, considers three types of GCs according to histologic features: intestinal, diffuse, and mixed types [15]. The diffuse type occurs more frequently in younger patients and in females compared with the intestinal type. Despite a decrease in the overall incidence of GC in recent decades, the incidence of the diffuse/mixed types increased tenfold between 1970 and 2000 [16-18], accounting for $35-45 \%$ of GC cases. Diffuse-type AGC is generally thought to have a worse prognosis and lower chemosensitivity than the intestinal type [19]. Recent reports showed a difference in PD-L1 expression among the different histological types [8, 20,21]. However, data on circulating and TILs in intestinal and diffuse/mixed AGC are lacking.

The aim of our study was to determine the immune status of AGC patients by analyzing circulating cells and TILs and compare the immune profile of patients with diffuse/mixed type and intestinal type. Analysis of immune circulating and tumor-infiltrating cells could provide different information. Indeed, circulating cells may reflect the general immune status of the patient and probably its ability to mount or maintain an efficient immune response against the tumor. The presence of immune cells in the tumor is linked to their capacity to migrate into the tumor but also for $\mathrm{T}$ cells to their priming. The prognostic value of these parameters has also been assessed.

\section{Materials and methods}

\section{Patients}

Patients with AGC enrolled in the multicenter PRODIGE 17-ACCORD 20 (MEGA) trial were asked to participate in this ancillary study. Patients with gastroesophageal junction or esophageal adenocarcinoma were not included in this immune cell analysis. To avoid heterogeneity and due to different epidemiology and pathogenesis [22], EGJA were excluded from the present analysis. The trial eligibility criteria and treatments were reported previously [22]. Briefly, patients with histologically proven, locally advanced or metastatic gastric adenocarcinoma with no prior treatment for advanced disease were eligible. Histological subtypes were reported according to the Lauren classification, assessed prospectively by the pathologist from the investigation center. Mixed type was defined by a dual pattern of differentiationglandular/solid (intestinal) and isolated-cell carcinoma (diffuse), according to the Lauren classification. We grouped together diffuse and mixed types to cover all the signet ring cell carcinomas according to the most recent World Health Organization (WHO) classification.

Assessment of circulating and intratumoral immune cells was planned in the initial design of the trial and was part of the full study protocol, with specific informed consent required for all patients participating in this ancillary study. The trial was registered with the US and French National Institutes of Health registries (NCT01443065, EudraCT No. 2009-012797-12). The study protocol was approved by a French national ethics committee. The results from the therapeutic trial were previously reported. All combination regimens reached the primary study endpoint for efficacy, with no major differences [22].

\section{Flow cytometry}

Peripheral blood samples were collected before the first treatment cycle. Peripheral blood mononuclear cells (PBMCs) were isolated from heparinized peripheral blood on Ficoll-Hypaque gradients as previously described [23]. Fresh PBMCs from patients were stained with antibodies targeting CD4 (clone OKT4; Biolegend), CD8 (clone HIT8a; Biolegend), CD25 (clone BC96, Invitrogen), CD127 (clone ebioRDR5; Thermo Fisher), CD3 (clone UCHT1; Thermo Fisher), CD19 (clone HCD56; Biolegend) and CD56, CD33 (clone WM53, Biolegend), HLA-DR (clone LN3; Biolegend), CD14 (clone 61D3, Thermo Fisher), and 
CD15 (clone HI98; Biolegend). Intracellular staining for anti-human FoxP3 (clone PCH101; Thermo Fisher) was done after fixation and permeabilization with the FoxP3 staining set (Thermo Fisher).

Isotype controls were used as negative controls. Dead cells were eliminated using the Live/Dead Fixable Aqua Dead Cell Kit (Thermo Fisher). Stained cells were analyzed on a LSRII cytofluorometer using FACS Diva (Becton Dickinson) and Flow-Jo Software (TreeStar).

\section{Pathology and immunohistochemistry (IHC)}

Four-micron sections of formalin-fixed, paraffin-embedded primary or metastatic GC tissue samples were submitted for TIL phenotyping with the following antibodies: anti-CD8 (clone SP16; Cell Marque, Rocklin, CA, USA), anti-FoxP3 (clone SP97;Thermo Fisher Scientific, Rockford, IL, USA) and anti-CD57 (clone NK-1; Cell Marque). Specimens were selected by the local pathologist. Centralized analysis was then performed by two independent observers. All IHC procedures were performed in a fully closed platform (BenchMark XT, Ventana/Roche). The number of TILs expressing each antigen was determined as the mean value of counts in each of three representative high-power microscopic fields, representing approximately $1 \mathrm{~mm}^{2}$ (field diameter/ surface $0.625 \mathrm{~mm} / 0.31 \mathrm{~mm}^{2}$, Axiophot 2, Carl Zeiss AG, Oberkochen, Germany).

When more than three fields were available, the "hotspot" method was used, consisting of selecting fields with the most abundant lymphocytic infiltration. The selection was done in the same manner in intestinal or diffuse/mixed type. Mismatch repair (MMR) tumor status was determined by IHC. MSI phenotype was defined by the loss of MLH1/ PMS2 or MSH2/MSH6.

\section{Statistical evaluation}

The median proportions of immune cells were compared between baseline characteristics using the Kruskal-Wallis test.

Overall survival (OS) was defined as the time from randomization to death, from any cause. OS was estimated by the Kaplan-Meier method. Patients alive at the time of analysis were censored on the date of last informative follow-up. Univariate and multivariate analyses were performed using the Cox proportional hazard model to estimate the hazard ratio (HR) and the 95\% confidence interval (CI). Comparisons were performed using the log-rank test. Median follow-up was estimated with the inverse Kaplan-Meier method.

A $p$ value less than 0.05 was regarded as significant. All statistical tests were two-sided.

The statistical analyses were performed using STATA Version 13 (Texas, USA).

\section{Results}

\section{Population and patient characteristics}

The PRODIGE 17-ACCORD 20 (MEGA) trial included 162 patients. After exclusion of patients with esophageal and gastroesophageal junction adenocarcinomas, 67 patients with AGC were included in the present ancillary study. The patient and disease characteristics at baseline are shown in Table 1. Circulating NK cells were analyzed in 47 patients, $\mathrm{CD} 4^{+} \mathrm{T}$ cells in $41, \mathrm{CD} 8^{+} \mathrm{T}$ cells in 42, Tregs in 47, and MDSCs in 52 (Fig. 1). Tumor sample (formalin-fixed, paraffin-embedded block with tumor tissue) was available in 51 patients, with a median number of H\&E slides of 5 (range 1-15). Concerning the TILs, 51 samples were analyzed for $\mathrm{CD}^{+}, 40$ for NK, and 49 for FoxP3. We were able to analyze MMR status

Table 1 Patient characteristics

\begin{tabular}{|c|c|c|}
\hline & $N$ & $\%$ \\
\hline \multicolumn{3}{|l|}{ Age (years) } \\
\hline Median (range) & $64(34-83)$ & \\
\hline \multicolumn{3}{|l|}{ Sex } \\
\hline Male & 33 & 49.3 \\
\hline Female & 34 & 50.7 \\
\hline \multicolumn{3}{|l|}{ ECOG } \\
\hline 0 & 19 & 28.8 \\
\hline 1 & 47 & 71.2 \\
\hline \multicolumn{3}{|l|}{ Lauren classification } \\
\hline Diffuse/mixed type & 27 & 40.3 \\
\hline Intestinal type & 40 & 59.7 \\
\hline \multicolumn{3}{|l|}{ Disease stage } \\
\hline Locally advanced & 1 & 1.5 \\
\hline 1 Metastatic site & 32 & 47.8 \\
\hline$>1$ Metastatic site & 34 & 50.7 \\
\hline \multicolumn{3}{|l|}{ Stage at diagnosis } \\
\hline Synchronous metastasis & 55 & 83.3 \\
\hline Metachronous metastasis & 11 & 16.7 \\
\hline \multicolumn{3}{|l|}{ Site of pathological diagnosis } \\
\hline Primitive tumor & 57 & 89.1 \\
\hline Metastasis & 6 & 9.3 \\
\hline NP & 1 & 1.6 \\
\hline \multicolumn{3}{|l|}{ Type of material } \\
\hline Biopsy specimen & 40 & 62.5 \\
\hline Operative specimen & 11 & 17.2 \\
\hline NA & 13 & 20.3 \\
\hline \multicolumn{3}{|l|}{ MMR status } \\
\hline MSI & 2 & 3.1 \\
\hline MSS & 35 & 54.7 \\
\hline ND & 27 & 42.2 \\
\hline
\end{tabular}




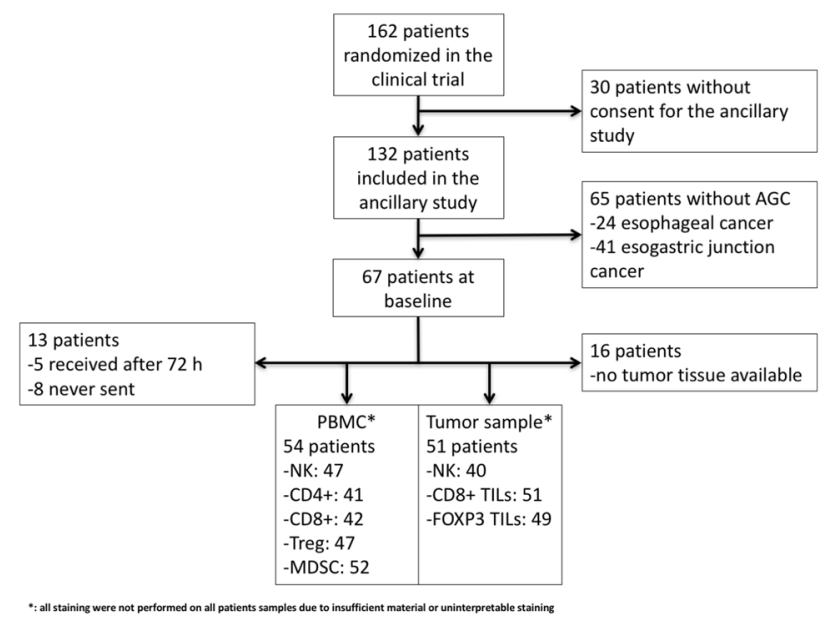

Fig. 1 Flowchart. Staining data were not available for all patient samples, because of insufficient material or uninterpretable staining

in 37 samples, the remaining were not interpretable due to insufficient material. MSI phenotype was found in 2 patients with intestinal type, and MSS phenotype in 35 patients (in 23 patients with intestinal type and 12 with diffuse/mixed type).

\section{Circulating immune cells}

Percentages of circulating effector cells in PBMCs were assessed by flow cytometry as follows: NK cells: $\mathrm{CD}_{6}{ }^{+} \mathrm{CD}^{-}{ }^{-} \mathrm{CD}^{+}{ }^{+} \mathrm{T}$ cells: $\mathrm{CD} 3^{+} \mathrm{CD} 4^{+} ; \mathrm{CD}^{+} \mathrm{T}$ cells: $\mathrm{CD}^{+}{ }^{+} \mathrm{CD} 8^{+}$(Suppl. Table 1). We previously reported the prognostic value of dynamic evolution of circulating tumor cells. (CTC) from patients of this study [24]. We did not find any correlation between CTC count and circulating immune cells (data not shown), within the limitation of small number of patients evaluated for both CTC and immune cells. Among effector cells, NK cell proportions were significantly lower in PBMCs of patients with diffuse/mixed-type GC than in those with intestinal-type GC (median $6.3 \%$ vs $11.5 \% ; p=0.02$ ) (Fig. 2; Suppl. Table 2). No differences were observed in $\mathrm{CD}^{+}{ }^{+} \mathrm{T}$ cell (median $37.1 \%$ vs $38.1 \% ; p=0.55$ ) and $\mathrm{CD} 8^{+} \mathrm{T}$ cell (median $21.9 \%$ vs $20.7 \% ; p=0.81$ ) percentages. The immunomodulatory CD56 $6^{\text {bright }}$ NK cell subset and NKT cells were not enriched within a specific pathological type. Immunosuppressive cells such as Tregs $\left(\mathrm{CD} 25^{\text {high }} \mathrm{CD} 127^{\text {low }} \mathrm{FoxP}^{+}\right.$in $\mathrm{CD} 4^{+}$cells) and $\mathrm{MDSC} \mathrm{CD}_{3}{ }^{+}\left(\mathrm{Lin}^{-}\right.$; $\left.\mathrm{CD}^{-}{ }^{-} \mathrm{CD} 19^{-} \mathrm{CD} 56^{-}\right)$were also assessed (Suppl. Table 1). Tregs were significantly lower in PBMCs of patients with diffuse/mixed-type GC compared with intestinal-type GC (median $3.3 \%$ vs $5.2 \%$; $p=0.03$ ), but not MDSCs (median 11.8\% vs 13.6\%; $p=0.71$ ) (Fig. 2; Suppl. Table 3). Thus, the general immune status of patients
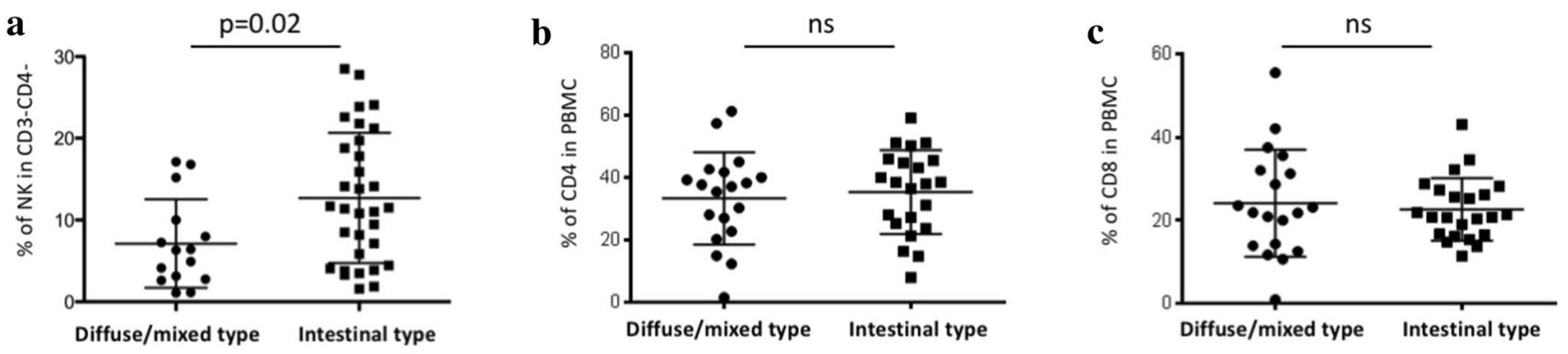

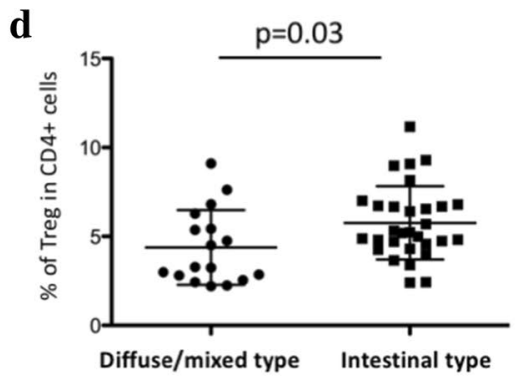

Fig. 2 Comparison of circulating cells between intestinal and diffuse/mixed-type AGC. The proportion of different subsets of effector immune cells was analyzed by flow cytometry in the peripheral blood of patients with diffuse and mixed-type or with intestinal-type AGC at diagnosis: a natural killer cell proportion $\left(\mathrm{CD}^{-} \mathrm{CD}^{-} 6^{+}\right.$cells $)$; b

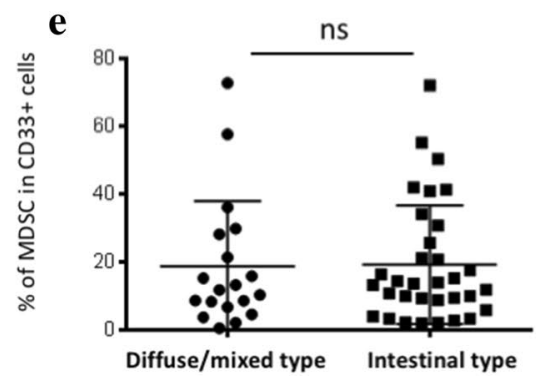

$\mathrm{CD} 4^{+} \mathrm{T}$ cell proportion $\left(\mathrm{CD} 3^{+} \mathrm{CD} 4^{+}\right.$cells); $\mathbf{c} \mathrm{CD} 8^{+} \mathrm{T}$ cell proportion $\left(\mathrm{CD}^{+} \mathrm{CD}^{-}\right.$cells); different subsets of regulatory cells were also analyzed: $\mathbf{d}$ Treg proportion $\left(\mathrm{CD} 25^{+} \mathrm{Foxp} 3^{+} \mathrm{CD} 127^{\text {lo }}\right.$ cells among $\mathrm{CD}^{+}$cells); e MDSC proportion (lin ${ }^{-} \mathrm{DR}^{-}$cells among $\mathrm{CD} 33^{+}$cells) 
with diffuse/mixed-type AGC differs from those with intestinal-type AGC, with a lower proportion of circulating NK cells and Tregs.

\section{Tumor-infiltrating immune cells}

We then assessed the presence of tumor-infiltrating immune cells $\left(\mathrm{CD} 8^{+}\right.$cells, $\mathrm{CD}^{+} 7^{+} \mathrm{NK}$ cells, and $\mathrm{FoxP}^{+}$cells), by IHC (Suppl. Table 2; Suppl. Figure 1).

Unlike circulating NK cells, tumor-infiltrating NK cells did not differ between the diffuse/mixed and intestinal types. However, the median number of NK cells infiltrating the tumors was very low (median 2.0 cells per field) (Suppl. Table 2). In comparison to infiltrating NK cells, the median number of $\mathrm{CD}^{+}{ }^{+}$cells and the median number of FoxP3 ${ }^{+}$ cells infiltrating the tumor was 15 times higher $\left(31 \mathrm{CD} 8^{+}\right.$ cells per field) and 20 times higher $\left(40\right.$ FoxP $3^{+}$cells per field), respectively. Infiltration of FoxP3-expressing cells did not correlate with histological type. However, the median number of $\mathrm{CD}^{+}$TILs was significantly lower in diffuse/ mixed-type AGC (21 cells per field) compared with intestinal-type AGC (59 cells per field), $p=0.009$ (Fig. 3; Suppl. Table 4). The significant difference between intestinal and diffuse/mixed-type AGC was still observed after excluding MSI tumors among tumors with MSS phenotype (Suppl. Figure 2). Thus, intestinal-type AGCs were more infiltrated by $\mathrm{CD} 8^{+} \mathrm{T}$ cells than diffuse/mixed-type AGCs.

\section{Prognostic impact of immune circulating and tumor-infiltrating cells}

Patients with NK cells $>17 \%$ (higher quartile) had a significantly longer OS compared with those with $\leq 17 \%$ NK cells in univariate analysis (HR $0.40 ; 95 \%$ CI [0.15-1.06]; $p=0.04$ ) (Fig. 4; Suppl. Table 5). Patients with NK $>17 \%$, adjusted for histological type, age, and ECOG performance status, had a non-significant trend
Impact of circulating NK cell proportion on overall survival

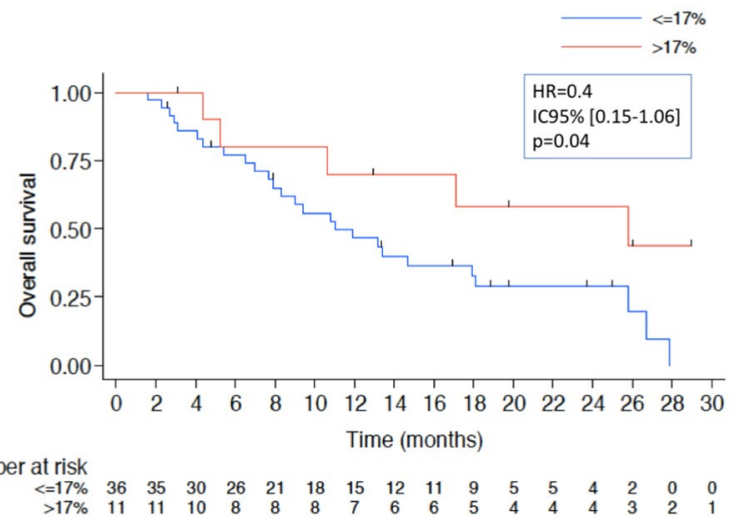

Fig. 4 Impact of circulating NK cell counts on overall survival 95\% CI

toward OS benefit in multivariate analyses (HR 0.45; $95 \%$ CI [0.16-1.27]; $p=0.13$ ) (Suppl. Table 5). The prognostic impact of circulating CD4 and CD8 was also analyzed but none were associated with OS. Immunosuppressive Treg cells and MDSCs were not prognostic factors of OS (Suppl. Table 5).

Concerning tumor-infiltrating cells, FoxP $3^{+}$cells had no prognostic effect (Suppl. Table 5). However, CD8 TILs were correlated with OS. OS for patients with more than $31 \mathrm{CD}^{+}$TILs per field (above the median) was significantly longer than OS for patients with $\leq 31 \mathrm{CD} 8^{+}$TILs (HR 0.44; 95\% CI [0.21-0.92]; $p=0.02$ ) (Fig. 5). In multivariate analysis with adjustment for pathological type, age, and ECOG performance status, the CD8 ${ }^{+}$TIL count was the only independent factor for OS (HR $0.42 ; 95 \%$ CI [0.18-0.96]; $p=0.039$ ) (Suppl. Table 5).

The association of CD8 TIL counts and OS was observed in the intestinal-type subgroup(HR $0.39 ; 95 \%$ CI [0.16-0.98]; $p=0.047)$. In the diffuse/mixed-type, patients
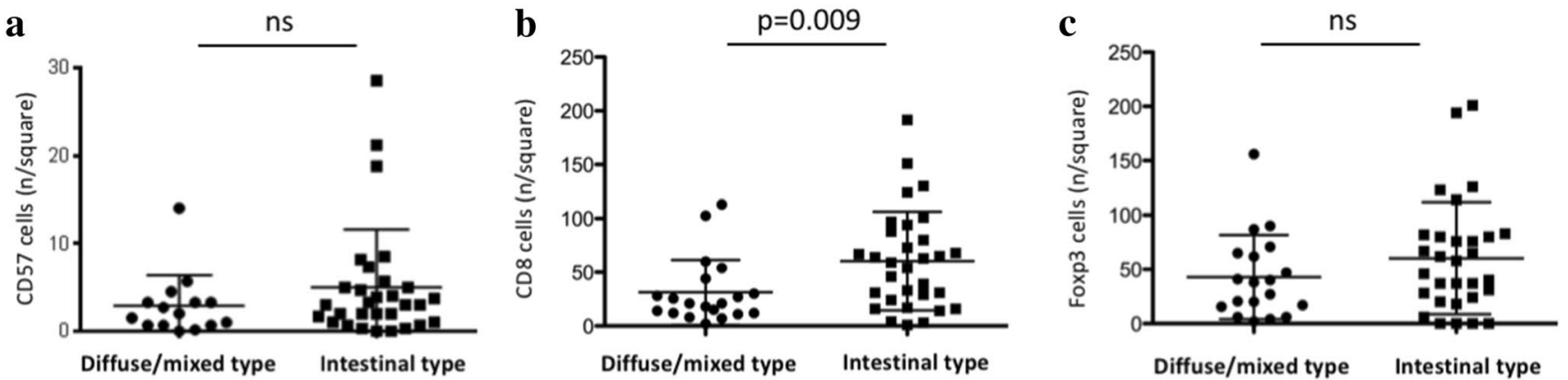

Fig. 3 Comparison of TI cells between intestinal and diffuse/mixedtype AGC. The count of different subsets of tumor-infiltrating effector and regulatory immune cells was analyzed in tumor samples of patients with diffuse- and mixed-type or with intestinal-type AGC at diagnosis, by immunohistochemistry: a natural killer cell count $\left(\mathrm{CD} 57^{+}\right.$cells); b $\mathrm{CD}^{+} \mathrm{T}$ cell count $\left(\mathrm{CD} 8^{+}\right.$cells $)$; c Treg count $\left(\right.$ Foxp $\left.^{+}\right)$ 


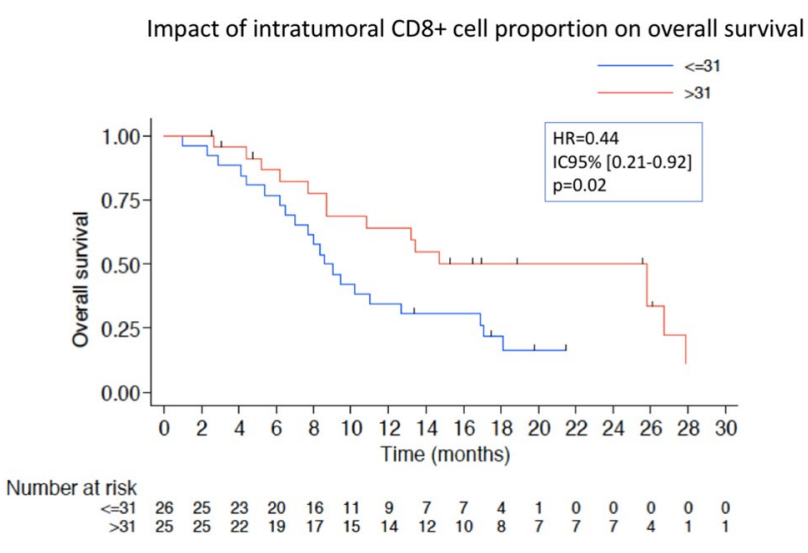

Fig. 5 Impact of intratumoral $\mathrm{CD}^{+}$cell counts on overall survival 95\% CI

with $>31 \mathrm{CD}^{+}$TILs per field tended to have better OS (HR 0.35; 95\% CI [0.08-1.60]; $p=0.13$ ).

\section{Discussion}

Gastric cancer is a heterogeneous disease and the two main histological tumor types (diffuse/mixed or intestinal) exhibit different outcomes. Immune cells have a pivotal role in controlling tumor development. In this study, we took advantage of a prospective, multicenter trial to compare the immune profile of patients with diffuse/mixed or intestinal AGC. We observed lower circulating NK cell and Treg proportions, as well as lower CD8 TILs in diffuse/mixed-type AGC than in intestinal-type AGC. Moreover, we showed that CD8 TILs and circulating NK cells have a prognostic role in OS in AGC, which supports the hypothesis that the innate and adaptive immune response could play a role in tumor control. As far as we know, our study is the first to show that immune cells occur in different proportions in diffuse/mixed and intestinal types of AGCs, and to provide evidence of the prognostic value of CD8 TILs and circulating NK cells in AGC.

In a study in AGC patients using RNAscope, PD-L1 had a decreased expression in diffuse GC compared to intestinaltype AGC [21]. Thus, our observations (low CD8 T cell infiltration) combined with other (low PD-L1) in diffusetype AGC can lead to hypothesize that diffuse-type AGC might be a "cold tumor" [25]. Furthermore, analysis of circulating cells showed that in diffuse-type NK cells and Treg are less abundant than in intestinal type. All these points suggest that diffuse type of AGC may represent an immunologically ignorant phenotype [26].

Several mechanisms contributing to this immunologically ignorant phenotype have been described in diffusetype AGC. First, a genomically stable tumor subtype enriched for the diffuse histological variant reportedly had a lower mutational load and did not exhibit PD-L1 expression [27]. Second, a lower expression of HLA-DR antigen, a class II HLA antigen, has been described in diffuse-type GC [28]. This lower expression may impair the antigenpresenting capability of antigen-presenting cells [29]. In addition to HLA class II, it could be of interesting to assess expression of class I HLA in further studies, which could specifically modulate antigen recognition to $\mathrm{CD} 8^{+} \mathrm{T}$ cell. Finally, an epithelial (E)-cadherin deficiency, due to CDH1 mutation, is a driver process in diffuse-type or signet ring cell carcinomas oncogenesis initiation [30]. In addition, E-cadherin also plays a role in $\mathrm{CD}^{+} \mathrm{T}$ cell accumulation in epithelial tissues [31]. Other components of the stroma and the tumor microenvironment content could be implied in the differential immune phenotype of diffuse and intestinal type. By example, Vascular Endothelial Growth Factor, key factor for angiogenesis, is also known to be an important modulator factor of immune cells such as Treg or of exhaustion of $\mathrm{CD} 8^{+} \mathrm{T}$ cells $[32,33]$. Tumor vasculature could also modulate migration of immune cells into the tumor [34]. Previous reports showed that VEGF expression and tumor is lower in diffuse-type compared to intestinal-type GC $[35,36]$. Other components as cancer-associated fibroblasts regulating TFG $\beta$ signaling have been described in diffuse-type GC and could be implied in the "cold tumor" phenotype [37]. Therefore, future studies providing an analysis of these different components and a correlation with TILs could be of interest to improve understanding of the mechanisms leading to low TILs infiltration of diffuse-type GC.

The immunologically ignorant phenotype of diffuse/ mixed-type AGC may also result in a lower sensitivity to immune checkpoint inhibitors of this tumor subtype. Successful anti-tumor immune response after PD-1/PD-L1 blockade requires reactivation and clonal proliferation of TILs [38], and is associated with tumor mutational load [21]. Recently, the results of the KEYNOTE 061 trial showed no benefit of pembrolizumab compared to palliative second-line chemotherapy in patients with AGC [13]. However, there was a trend toward pembrolizumab efficacy in intestinal-type AGC patients (HR 0.66; 95\% CI [0.40-1.11]), but not in those with diffuse-type AGC (HR $0.88 ; 95 \%$ CI [0.54-1.45]).

In our study, the prognostic value of CD8 TILs and circulating NK cells regarding survival underlies the clinical meaning of the different immune subsets in diffuse-type and intestinal-type AGCs. The impact of CD8 TILs was maintained in the intestinal-type subgroup, with a nonsignificant trend observed in the diffuse/mixed subgroup. This suggests that survival may depend more on CD8 infiltration than histological type, which was not per se prognostic in our study. Therefore, a lower CD8 infiltration in 
patients with diffuse-type tumors in our study may partly explain the worse prognosis observed compared to other studies.

The role of NK cells is well known in resected GC. Several studies have reported an increased OS in patients with a high intratumoral number of NK cells [39-41]. In our study, we found that circulating NK cells had a prognostic role in OS, but not intratumoral NK cells. The low impact of intratumoral NK cells could be due to the low infiltration of NK cells in metastatic GC compared with localized GC. We did not find any association between other immune cell subsets and survival, in particular with Tregs and MDSCs. The prognostic impact of Tregs remains controversial in GC, with studies reporting contrasting results [5].

The limited number of patients with available tumor samples in our study is a clear limitation of the present work. Moreover, the small tumor samples received for some patients allowed us to do only part of the planned analyses for some specimens. This may have prevented both the detection of the prognostic value of other immune cells and the analysis of the immune signature by combining parameters. Moreover, tumor biopsies, used for IHC assessments, may not represent the intratumoral heterogeneity. Finally, MSI tumors and EBV-positive cancers have been shown to be crucial predictors of efficacy of immunotherapy in gastric cancer and to have increased TILs. Due to poor availability of tumor tissue, we did not assessed EBV status, and cannot exclude that it could be confounding factors, even if EBV gastric cancer are generally estimated to be only $5-10 \%$ [42]. However, in our study, MSI phenotype was found in only two specimen and the high TILs infiltration in intestinal compared to diffuse/mixed was observed regardless the MMR status. In conclusion, our study in patients prospectively randomized in a multicenter clinical trial shows that diffuse/mixed-type AGC has lower local and systemic immunogenicity, with a decreased number of effector CD8 TILs and circulating NK cells, but also decreased immunosuppressive Tregs compared to intestinal GC. This suggests that diffuse/mixed AGC could be an immunologically ignorant tumor. This immunological profile could contribute to a worse prognosis in patients with diffuse-type AGC and a lower sensitivity to immunotherapy. If these results are confirmed, the efficacy of immunotherapies will need to be evaluated according to the histological/pathological type of AGC. In particular, combined treatment to overcome some mechanisms of immune ignorance, such as CAR T Cells [43], may be of interest in diffuse-type AGC and should be evaluated. Moreover, our study is the first to demonstrate the prognostic implication of $\mathrm{CD} 8^{+}$TILs and circulating NK cells in AGC, providing a crucial rationale for immunotherapies in intestinal-type AGC.

Acknowledgements This work was supported by Amgen.
Funding The funding source had no involvement in study design, the collection, or analysis and interpretation of data.

\section{Compliance with ethical standards}

Conflict of interest Dr. Pernot reports grants from Amgen, during the conduct of the study; personal fees and non-financial support from Amgen, personal fees and non-financial support from Servier, nonfinancial support from Bayer, outside the submitted work. Dr. Terme reports personal fees from Roche, personal fees from Gilead, outside the submitted work. Dr. Badoual reports personal fees from Roche, MSD, personal fees from Astrazeneca, personal fees from BMS, outside the submitted work. Dr. Penault-Llorca reports personal fees from Roche/Ventana, personal fees from Amgen, outside the submitted work. Dr. BOUCHE reports personal fees from ROCHE, personal fees from AMGEN, personal fees from MERCK, personal fees from SERVIER, personal fees from LILLY, personal fees from BAYER, personal fees from PIERRE FABRE, outside the submitted work. Dr. Bennouna reports personal fees from Roche, personal fees from Boehringer-Ingelheim, personal fees from Astra-Zeneca, personal fees from AMGEN, personal fees from Novartis, personal fees from BMS, outside the submitted work. Dr. FRANCOIS reports personal fees and non-financial support from Roche, personal fees and non-financial support from Servier, personal fees from Merck, personal fees from Amgen, personal fees from Sanofi, personal fees from Novartis, personal fees from Bayer, outside the submitted work. Dr. de la Fouchardière reports personal fees and non-financial support from Amgen, outside the submitted work. Dr. SAMALIN reports personal fees and non-financial support from AMGEN, outside the submitted work. Dr. BACHET reports personal fees and non-financial support from Amgen, personal fees from Bayer, personal fees from Celgene, personal fees and non-financial support from Merck Serono, personal fees and non-financial support from Roche, personal fees from Sanofi, personal fees and non-financial support from Servier, personal fees from Shire, outside the submitted work. Dr Ghiringhelli reports personal fees from Servier, personal fees from Roche, personal fees from Amgen, personal fees from Merck Serono, personal fees from Sanofi outside the submitted work. Dr. Malka reports grants and non-financial support from Amgen, during the conduct of the study; personal fees and nonfinancial support from Amgen, personal fees and non-financial support from Bayer, personal fees and non-financial support from Merck, personal fees and non-financial support from Merck Serono, personal fees and non-financial support from Roche, personal fees and non-financial support from Sanofi, personal fees and non-financial support from Servier, personal fees from Shire, personal fees from Halio Dx, personal fees from Agios, outside the submitted work. Dr Taieb reports personal fees from: Celgene, Servier, Roche, Amgen, Merck Serono, MSD, SIRTEX, Lilly, Sanofi, outside the submitted work. Dr. Voron, Dr Castan, Dr Gourgou, Dr Radosevic-Robin, Dr Borg, Dr Stanbury, Dr Tartour, Dr Boige, and Dr Marcheteau have nothing to disclose.

\section{References}

1. Ferlay J, Soerjomataram I, Dikshit R, Eser S, Mathers C, Rebelo $\mathrm{M}$, et al. Cancer incidence and mortality worldwide: sources, methods and major patterns in GLOBOCAN 2012. Int J Cancer. 2015;136:E359-386. https://doi.org/10.1002/ijc.29210.

2. Zou W. Regulatory T cells, tumour immunity and immunotherapy. Nat Rev Immunol. 2006;6:295-307. https://doi.org/10.1038/nri18 06.

3. Gabrilovich DI. Myeloid-derived suppressor cells. Cancer Immunol Res. 2017;5:3-8. https://doi.org/10.1158/2326-6066. CIR-16-0297. 
4. Lee HE, Chae SW, Lee YJ, Kim MA, Lee HS, Lee BL, et al. Prognostic implications of type and density of tumour-infiltrating lymphocytes in gastric cancer. Br J Cancer. 2008;99:1704-11. https://doi.org/10.1038/sj.bjc.6604738.

5. Kang BW, Kim JG, Lee IH, Bae HI, Seo AN. Clinical significance of tumor-infiltrating lymphocytes for gastric cancer in the era of immunology. World J Gastrointest Oncol. 2017;9:293-9. https:// doi.org/10.4251/wjgo.v9.i7.293.

6. Arigami T, Uenosono Y, Ishigami S, Matsushita D, Hirahara T, Yanagita $\mathrm{S}$, et al. Decreased density of $\mathrm{CD}^{+}$tumor-infiltrating lymphocytes during gastric cancer progression. J Gastroenterol Hepatol. 2014;29:1435-41.

7. Gulubova M, Manolova I, Kyurkchiev D, Julianov A, Altunkova I. Decrease in intrahepatic $\mathrm{CD}_{5} 6^{+}$lymphocytes in gastric and colorectal cancer patients with liver metastases. APMIS Acta Pathol Microbiol Immunol Scand. 2009;117:870-9. https://doi.org/10.1 111/j.1600-0463.2009.02547.x.

8. Xing X, Guo J, Wen X, Ding G, Li B, Dong B, et al. Analysis of PD1, PDL1, PDL2 expression and T cells infiltration in 1014 gastric cancer patients. Oncoimmunology. 2018;7:e1356144. https ://doi.org/10.1080/2162402X.2017.1356144.

9. Haanen JBAG, Baars A, Gomez R, Weder P, Smits M, de Gruijl TD, et al. Melanoma-specific tumor-infiltrating lymphocytes but not circulating melanoma-specific $\mathrm{T}$ cells may predict survival in resected advanced-stage melanoma patients. Cancer Immunol Immunother CII. 2006;55:451-8. https://doi.org/10.1007/s0026 2-005-0018-5.

10. Janjigian YY, Ott PA, Calvo E, Kim JW, Ascierto PA, Sharma P, et al. Nivolumab \pm ipilimumab in pts with advanced (adv)/metastatic chemotherapy-refractory $(\mathrm{CTx}-\mathrm{R})$ gastric $(\mathrm{G})$, esophageal (E), or gastroesophageal junction (GEJ) cancer: CheckMate 032 study. J Clin Oncol. 2017;35:4014-4014. https://doi.org/10.1200/ JCO.2017.35.15_suppl.4014.

11. Fuchs CS, Doi T, Jang RW, Muro K, Satoh T, Machado M, et al. Safety and efficacy of pembrolizumab monotherapy in patients with previously treated advanced gastric and gastroesophageal junction cancer: phase 2 clinical KEYNOTE-059 trial. JAMA Oncol. 2018;4:e180013. https://doi.org/10.1001/jamao ncol.2018.0013.

12. Kang Y-K, Boku N, Satoh T, Ryu M-H, Chao Y, Kato K, et al. Nivolumab in patients with advanced gastric or gastro-oesophageal junction cancer refractory to, or intolerant of, at least two previous chemotherapy regimens (ONO-4538-12, ATTRACTION2): a randomised, double-blind, placebo-controlled, phase 3 trial. Lancet Lond Engl. 2017;390:2461-71. https://doi.org/10.1016/ S0140-6736(17)31827-5.

13. Shitara K, Özgüroğlu M, Bang Y-J, Di Bartolomeo M, Mandalà M, Ryu M-H, et al. Pembrolizumab versus paclitaxel for previously treated, advanced gastric or gastro-oesophageal junction cancer (KEYNOTE-061): a randomised, open-label, controlled, phase 3 trial. Lancet Lond Engl. 2018;392:123-33. https://doi. org/10.1016/S0140-6736(18)31257-1.

14. Bang Y-J, Ruiz EY, Van Cutsem E, Lee K-W, Wyrwicz L, Schenker M, et al. Phase 3, randomised trial of avelumab versus physician's choice of chemotherapy as third-line treatment for patients with advanced gastric or gastro-oesophageal junction cancer: primary analysis of JAVELIN Gastric 300. Ann Oncol. 2018. https ://doi.org/10.1093/annonc/mdy264.

15. Lauren $P$. The two histological main types of gastric carcinoma: diffuse and so-called intestinal-type carcinoma. An attempt at a histo-clinical classification. Acta Pathol Microbiol Scand. 1965;64:31-49.

16. Bamboat ZM, Tang LH, Vinuela E, Kuk D, Gonen M, Shah MA, et al. Stage-stratified prognosis of signet ring cell histology in patients undergoing curative resection for gastric adenocarcinoma.
Ann Surg Oncol. 2014;21:1678-85. https://doi.org/10.1245/s1043 4-013-3466-8.

17. Taghavi S, Jayarajan SN, Davey A, Willis AI. Prognostic significance of signet ring gastric cancer. J Clin Oncol. 2012;30:3493-8. https://doi.org/10.1200/JCO.2012.42.6635.

18. Henson DE, Dittus C, Younes M, Nguyen H, Albores-Saavedra J. Differential trends in the intestinal and diffuse types of gastric carcinoma in the United States, 1973-2000: increase in the signet ring cell type. Arch Pathol Lab Med. 2004;128:765-70. https://doi.org/10.1043/1543-2165(2004)128\%3c765:DTITI A\%3e2.0.CO;2.

19. Pernot S, Voron T, Perkins G, Lagorce-Pages C, Berger A, Taieb J. Signet-ring cell carcinoma of the stomach: impact on prognosis and specific therapeutic challenge. World J Gastroenterol. 2015;21:11428-38. https://doi.org/10.3748/wjg.v21.i40.11428.

20. Li Z, Lai Y, Sun L, Zhang X, Liu R, Feng G, et al. PD-L1 expression is associated with massive lymphocyte infiltration and histology in gastric cancer. Hum Pathol. 2016;55:182-9. https://doi. org/10.1016/j.humpath.2016.05.012.

21. Yuan J, Zhang J, Zhu Y, Li N, Tian T, Li Y, et al. Programmed death-ligand-1 expression in advanced gastric cancer detected with RNA in situ hybridization and its clinical significance. Oncotarget. 2016;7:39671-9. https://doi.org/10.18632/oncotarget.9381.

22. Malka D, Castan F, Francois E, Bouche O, Bennouna J, Ghiringhelli $\mathrm{F}$, et al. FOLFOX alone or combined to rilotumumab or panitumumab as first-line treatment in patients (pts) with advanced gastroesophageal adenocarcinoma (AGEA): an open-label, randomized phase II trial (PRODIGE 17 ACCORD 20 MEGA). J Clin Oncol. 2015;33:4013-4013. https://doi.org/10.1200/ jco.2015.33.15_suppl.4013.

23. Fuss IJ, Kanof ME, Smith PD, Zola H. Isolation of whole mononuclear cells from peripheral blood and cord blood. Curr Protoc Immunol. 2009; 7(Unit 7):1. https://doi.org/10.1002/0471142735 .im0701s85.

24. Pernot S, Badoual C, Terme M, Castan F, Cazes A, Bouche O, et al. Dynamic evaluation of circulating tumour cells in patients with advanced gastric and oesogastric junction adenocarcinoma: prognostic value and early assessment of therapeutic effects. Eur J Cancer Oxf Engl. 1990;2017(79):15-22. https://doi.org/10.1016/j. ejca.2017.03.036.

25. van der Woude LL, Gorris MAJ, Halilovic A, Figdor CG, de Vries IJM. Migrating into the tumor: a roadmap for $\mathrm{T}$ cells. Trends Cancer. 2017;3:797-808. https://doi.org/10.1016/j.treca n.2017.09.006.

26. Hegde PS, Karanikas V, Evers S. The where, the when, and the how of immune monitoring for cancer immunotherapies in the era of checkpoint inhibition. Clin Cancer Res. 2016;22:1865-74. https://doi.org/10.1158/1078-0432.CCR-15-1507.

27. Cancer Genome Atlas Research Network. Comprehensive molecular characterization of gastric adenocarcinoma. Nature. 2014;513:202-9. https://doi.org/10.1038/nature13480.

28. Teh M, Lee YS. HLA-DR antigen expression in intestinal-type and diffuse-type gastric carcinoma. Cancer. 1992;69:1104-7.

29. Rodríguez JA. HLA-mediated tumor escape mechanisms that may impair immunotherapy clinical outcomes via T-cell activation. Oncol Lett. 2017;14:4415-27. https://doi.org/10.3892/ ol.2017.6784.

30. Humar B, Blair V, Charlton A, More H, Martin I, Guilford P. E-cadherin deficiency initiates gastric signet-ring cell carcinoma in mice and man. Cancer Res. 2009;69:2050-6. https://doi. org/10.1158/0008-5472.CAN-08-2457.

31. Hofmann M, Pircher H. E-cadherin promotes accumulation of a unique memory CD8 T-cell population in murine salivary glands. Proc Natl Acad Sci USA. 2011;108:16741-6. https://doi. org/10.1073/pnas.1107200108. 
32. Terme M, Pernot S, Marcheteau E, Sandoval F, Benhamouda $\mathrm{N}$, Colussi $\mathrm{O}$, et al. VEGFA-VEGFR pathway blockade inhibits tumor-induced regulatory T-cell proliferation in colorectal cancer. Cancer Res. 2013;73:539-49. https://doi.org/10.1158/0008-5472. CAN-12-2325.

33. Voron T, Colussi O, Marcheteau E, Pernot S, Nizard M, Pointet A-L, et al. VEGF-A modulates expression of inhibitory checkpoints on $\mathrm{CD}^{+} \mathrm{T}$ cells in tumors. J Exp Med. 2015;212:139-48. https://doi.org/10.1084/jem.20140559.

34. Tartour E, Pere H, Maillere B, Terme M, Merillon N, Taieb J, et al. Angiogenesis and immunity: a bidirectional link potentially relevant for the monitoring of antiangiogenic therapy and the development of novel therapeutic combination with immunotherapy. Cancer Metastasis Rev. 2011;30:83-95. https://doi. org/10.1007/s10555-011-9281-4.

35. Takahashi Y, Cleary KR, Mai M, Kitadai Y, Bucana CD, Ellis LM. Significance of vessel count and vascular endothelial growth factor and its receptor (KDR) in intestinal-type gastric cancer. Clin Cancer Res. 1996;2:1679-84.

36. Ohtani H, Nagura H. Differing microvasculature in the two major types of gastric carcinoma: a conventional, ultrastructural and ultrastructural immunolocalization study of von Willebrand factor. Virchows Arch A Pathol Anat Histopathol. 1990;417:29-35.

37. Ishimoto T, Miyake K, Nandi T, Yashiro M, Onishi N, Huang KK, et al. Activation of transforming growth factor beta 1 signaling in gastric cancer-associated fibroblasts increases their motility, via expression of rhomboid 5 homolog 2 , and ability to induce invasiveness of gastric cancer cells. Gastroenterology. 2017;153(191204):e16. https://doi.org/10.1053/j.gastro.2017.03.046.
38. O’Donnell JS, Long GV, Scolyer RA, Teng MWL, Smyth MJ. Resistance to PD1/PDL1 checkpoint inhibition. Cancer Treat Rev. 2017;52:71-81. https://doi.org/10.1016/j.ctrv.2016.11.007.

39. Ishigami $S$, Natsugoe $S$, Tokuda $K$, Nakajo A, Che X, Iwashige H, et al. Prognostic value of intratumoral natural killer cells in gastric carcinoma. Cancer. 2000;88:577-83.

40. Ishigami S, Natsugoe S, Tokuda K, Nakajo A, Xiangming C, Iwashige $\mathrm{H}$, et al. Clinical impact of intratumoral natural killer cell and dendritic cell infiltration in gastric cancer. Cancer Lett. 2000;159:103-8.

41. Rosso D, Rigueiro MP, Kassab P, Ilias EJ, Castro OAP, Novo $\mathrm{NF}$, et al. Correlation of natural killer cells with the prognosis of gastric adenocarcinoma. Arq Bras Cir Dig ABCD Braz Arch Dig Surg. 2012;25:114-7.

42. Naseem M, Barzi A, Brezden-Masley C, Puccini A, Berger MD, Tokunaga R, Battaglin F, Soni S, McSkane M, Zhang W, Lenz HJ. Outlooks on Epstein-Barr virus associated gastric cancer. Cancer Treat Rev. 2018;66:15-22.

43. Dolcetti R, De Re V, Canzonieri V. Immunotherapy for gastric cancer: time for a personalized approach? Int J Mol Sci. 2018. https://doi.org/10.3390/ijms19061602.

Publisher's Note Springer Nature remains neutral with regard to jurisdictional claims in published maps and institutional affiliations.

\section{Affiliations}

\section{Simon Pernot ${ }^{1,2}$ - Magali Terme ${ }^{1} \cdot$ Nina Radosevic-Robin ${ }^{3} \cdot$ Florence Castan $^{4}$. Cécile Badoual ${ }^{1,5} \cdot$ Elie Marcheteau $^{1}$. Fréderique Penault-Llorca ${ }^{3}$. Olivier Bouche ${ }^{6}$. Jaafar Bennouna ${ }^{7}$. Eric Francois ${ }^{8}$. Francois Ghiringhelli ${ }^{9}$. Christelle De La Fouchardiere ${ }^{10}$. Emmanuelle Samalin ${ }^{11}$. Jean Baptiste Bachet ${ }^{12}$. Christophe Borg ${ }^{13}$. Valérie Boige $^{14}$. Thibault Voron ${ }^{1} \cdot$ Trevor Stanbury $^{15}$. Eric Tartour ${ }^{1}$. Sophie Gourgou ${ }^{4}$. David Malka ${ }^{14}$. Julien Tai $e^{1,2}$}

1 Université de Paris, PARCC, INSERM, 75015 Paris, France

2 Hôpital Européen Georges-Pompidou, APHP; Department of GI oncology, Université de Paris, Paris, France

3 Department of Biopathology, Centre Jean Perrin and University Clermont Auvergne/INSERM U1240, Clermont-Ferrand, France

4 Biometrics Unit, Institut du Cancer Montpellier-Val d'Aurelle, Université de Montpellier, Montpellier, France

5 Department of Pathology, Université de Paris, Sorbonne Paris Cité, Paris, France

6 CHU Robert Debré, Reims, France

7 Institut de Cancérologie de l'Ouest-Site René Gauducheau, Saint Herblain, France

8 Centre Antoine-Lacassagne, Nice, France
9 Centre Georges-François Leclerc, Dijon, France

10 Centre Léon Bérard, Lyon, France

11 Institut du Cancer Montpellier-Val d'Aurelle, Université de Montpellier, Montpellier, France

12 Pitié Salpétrière Hospital, Paris, France

13 Medical Oncology Unit, CHU Minjoz, Besancon, France

14 Département de Médecine Oncologique, Gustave Roussy, Université Paris-Saclay, 94805 Villejuif, France

15 UNICANCER, Paris, France 